set out does, however, permit the conclusion that the common raspberry aphids, Amphorophora rubi Kalt. and Aphis idoei V.d.G. are capable of acting as vectors of certain raspberry viruses under Scottish conditions.

The investigation, of which this work forms a part, is financed by a grant from the Agricultural Research Council, to which our acknowledgments are therefore due.

C. H. Cadman

A. R. HiLL

Scottish Raspberry Investigation,

(East Malling Research Station),

c/o University College,

Dundee. Sept. 1.

${ }^{1}$ Harris, R. V., J. Pom. and Hort. Sci., 11, 237 (1933).

* Harris, R. V., J. Pom. and Hort. Sci, 17, 318 (1940).

${ }^{2}$ Dicker. G. H. L., J. Pom. and Hort. Sei., 18, 275 (1940).

\section{Optimum pH and Temperature, and Energy of Activation of the Transamination between Glutamic Acid and Pyruvic Acid}

Is a previous paper ${ }^{1}$ I stated that the process :

glutamic acid + pyruvic acid $\underset{b}{\stackrel{a}{\rightleftarrows}}$

$\alpha$-ketoglutaric acid + alanine . . . . (1)

reaches an equilibrium through a first-order reaction according to the equation :

$$
\log _{e}\left(1-\alpha / \alpha_{0}\right)=-k t .
$$

In this, $k$ is the velocity coefficient, $t$ the time measured in seconds, $\alpha$ the degree of reaction at the time $t$, and $\alpha_{0}$ at the time $t=\infty$, when the equilibrium has been attained. In the temperature interval $15^{\circ}-70^{\circ}$ and at $p H 7 \cdot 5, \alpha_{0}=0.60$ for reaction $(1 a)$ and $\alpha_{0}=$ 0.40 for $(1 b)$.

Using $k$ as a measure of the strength of the enzyme (alanine-glutamic transaminase), it is possible to determine in an absolutely unambiguous way the relation between enzyme activity and $p \mathrm{H}$ or temperature.

The enzyme was prepared by extraction of minced ox hearts with $1 / 15 M$ phosphate buffer $(p H 7 \cdot 5)$. The liquid is pressed through a linen cloth and half saturated with ammonium sulphate. The precipitate containing the enzyme is filtered off, suspended in water and dialysed in a 'Cellophane' tube against running tap water. The undissolved residuum is centrifuged off and discarded. The solution is heated at $60^{\circ}$ for $10 \mathrm{~min}$. The heat-coagulated protein is centrifuged off and the clear supernatant liquid is

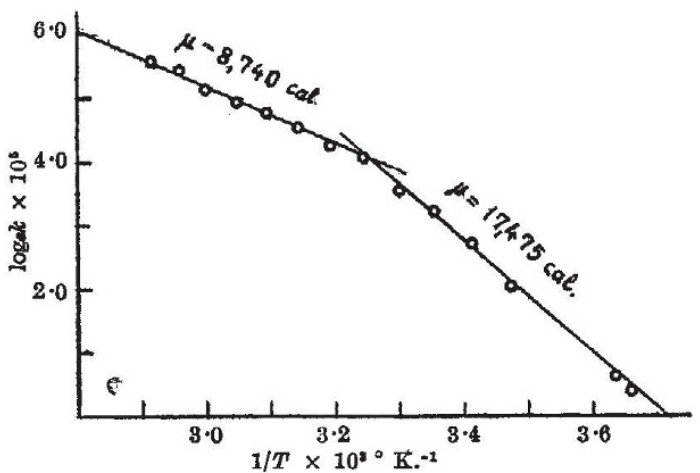
AN ARRHENIUS PLOT OF THE FFFECTS OF TRMPERATURE OPON THE GLUTAMIO-ATANINE TRANSAMTNASE SYSTEM. THF FNERGIES
OF AOTIVATION ARE OALOULATED FROM THE SLOPE OF' THR LINRS used in what follows. The determination of $k$ is carried out as previously described ${ }^{1}$. The concentration of substrate in the reaction mixture (enzyme + substrate + buffer) is $0.0167 M$ with regard to aminoand keto-acids.

Using $k$ as a measure of the enzyme strength, it appears that the reaction has a maximum of velocity at $p H \mathbf{H} \cdot \mathbf{5}$ in accordance with Kritzmann's result ${ }^{2}$. The velocity is very sensitive to changes in $p \mathrm{H}$; altering $p \mathrm{H}$ from 7 to $7 \cdot 5$ increases $k$ about threefold. In a similar manner the optimum temperature is found to be $75^{\circ} \mathrm{C}$. In order to decide whether the enzyme reaction follows the Arrhenius equation, $\log _{e} k \times 10^{5}$ is plotted against the reciprocal absolute temperature $\left(1 / T \times 10^{3}\right)$ as shown in the accompanying graph. A sharp break in the relationship occurs at $34^{\circ}$. It is apparent that the reaction follows the Arrhenius equation accurately from $0^{\circ}$ to $34^{\circ}$ with an energy of activation of $17,475 \mathrm{cal}$., and from $34^{\circ}$ to $70^{\circ}$ with an energy of activation of $8,740 \mathrm{cal}$. Such a shift at a critical temperature has been reported previously with regard to other enzyme systems ${ }^{3}$.

The energy of activation and $Q_{10}$ for the alanineglutamic transaminase system as reported by me earlier ${ }^{1}$ is no longer relevant, as the temperature interval in which the two constants are computed $\left(25-35^{\circ}\right)$ includes the critical temperature.

Biochemical Institute,

University of Aarhus. May 18.

${ }^{1}$ Darling, S., Acta Physiol. Scand., 10, 150 (1945).

"Kritzmann, M. G., Biochimiya, 3, 603 (1940) ; B. ges. Physiol., 11\%, $293(1940)$.

"Sizer, I. W., "Advances in Enzymology", 3, 35 (1943).

\section{Visual Cells of the Guinea Pig}

O'DAY has pointed out ${ }^{1}$ that his histological preparations provide definite evidence for the presence of cones in the retina of the guinea pig. I welcome this statement, although I have myself, as he indicated, relied on authors who have denied it. Occasionally one finds evidence for red modulators in the eye of the guinea pig (see, for example, Fig. 140 , p. 281 , of my recent summary ${ }^{2}$ ). Such modulators, I maintain, should be ascribed to cones if the histological differentiation of the cells into rods and cones is going to mean anything at all to retinal physiology. There are more of them in the eye of the rat. Since, however, some histologists deny the presence of cones in the eye of the rat (see ref. 2), and others refuse to accept them in the guinea pig, the physiologist must try to stand on his own feet.

$I$ have suggested ${ }^{2}$ that the red modulators in the eye of the rat are due to cones. But cones cannot be as important in the eyes of the guinea pig and the rat as in the retina of the cat. The latter has a very much greater number of the on/off-elements typical for cones (80 per cent); at least 36 per cent of the elements show a complete Purkinje shift with light adaptation. I have never found such Purkinje shifts in the eyes of rats and guinea pigs ${ }^{2}$.

\section{RagNar Granit}

Nobel Institute for Neurophysiology, Karolinska Institutet, Stockholm.

Nov. 12.

'O'Day, K., Nature, 160, 648 (1947).

"Granit, R., "Sensory Mechanisms of the Retina" (Oxford Univ Press, 1947). 